\title{
Cost-optimal Scheduling of Nuclear Component Maintenance Subject to Reliability Constraints
}

\author{
Mari Ito ${ }^{*}$, Masaaki Suzuki ${ }^{\dagger}$
}

\begin{abstract}
Preventive maintenance is a key element in the maintenance policy of many industries, including the power sector. To achieve the reasonable and effective maintenance of nuclear power plants (NPPs), proper aging management is crucial and should be optimized from the viewpoints of both safety and economy. To this end, we propose a mixed-integer maintenance-scheduling model that minimizes the total cost of maintenance activities over the lifetime of an NPP while ensuring the reliability of safety-critical functions. Built into the model is the recognition that effective maintenance activities differ depending on the cause of the latent failure and that the cost associated with maintenance varies depending on the type of maintenance activity. The value of the proposed model is demonstrated by applying it to an illustrative case in which optimal maintenance schedules for a single representative system component are produced. Importantly, the model enables the user to quantitatively evaluate the tradeoff between the reliability of safety-critical functions and total maintenance cost.
\end{abstract}

Keywords: maintenance, mixed-integer programming model, nuclear power plant, reliability, scheduling

\section{Introduction}

Preventive maintenance is a common practice in many industries, including the power sector. To ensure the effective maintenance of nuclear power plants (NPPs), the management of component aging is of critical importance and should be optimized from the viewpoints of both safety and economy. However, maintenance scheduling is typically conducted manually, and it is a time- and resource-consuming process because of the large number of components and constraints that must be considered when creating a maintenance schedule. The fact that most maintenance requirements are checked manually means that there is substantial room for improvement in the scheduling process.

Prajapat et al. provide a comprehensive literature review in the field of maintenancescheduling optimization, particularly for power plant applications [1]. Although a limited number of studies have addressed maintenance scheduling for single power plants, most

* Tokyo University of Science, Chiba, Japan

$\dagger$ Chukyo University, Aichi, Japan 
have focused on the generator-maintenance scheduling problem. Reference [2] formulated the problem of finding the minimum-cost maintenance schedule for NPP standby safety systems as a dynamic programming problem. The application of this formulation was demonstrated for the 10-component high-pressure injection system (HPIS) of a pressurized water reactor (PWR). References [3] and [4] also proposed metaheuristic approaches for maintenance-scheduling optimization that maximizes the availability of an NPP subsystem for a given period. They applied particle swarm optimization and a genetic algorithm to the HPIS and emergency core cooling system of a PWR to demonstrate the usefulness of their proposed methods.

The relationship between individual maintenance activities and the reliability of safetycritical functions can be appropriately evaluated by establishing the component failure rate considering the influence of aging and maintenance activities. One of the authors of this study developed a component failure rate model which recognizes the reality that effective maintenance activities will differ depending on the cause of the latent failure [5]. Subsequently, [6] proposed a maintenance-scheduling model that incorporates this failure rate model. However, the proposed model minimizes the total number of maintenance activities performed and fails to accommodate the fact that the cost associated with maintenance depends on the type of maintenance being performed.

In this study, we propose a maintenance-scheduling model that minimizes the total cost of maintenance activities over the lifetime of an NPP while ensuring the reliability of safetycritical functions. We formulate the maintenance-scheduling problem as a mixed-integer programming problem and consider that the cost associated with maintenance will differ depending on the nature of the maintenance activity (for example, overhaul inspection vs. replacement).

\section{Model}

\subsection{Failure Rate Model}

In the proposed model, the various component failure rates are determined by considering the influence of aging and maintenance activities, following the principles presented in [5]. To determine the failure rate of a particular component, the failure rate for a specific failure mode, $\lambda$, is first broken down into the failure rates for each possible cause $i, \lambda_{i}$, based on the number of past occurrences of each cause, $n_{i}$; that is, $\lambda_{i}=\lambda \cdot n_{i} / \Sigma_{i} n_{i}$. The historical failure rate for each failure mode, along with the number of occurrences of each failure cause, can be found in databases such as the NUClear Information Archives (NUCIA) database [7]. Next, time dependence is considered, and the increase or decrease in the failure rate due to various maintenance activities can be evaluated. It is here that we allow for the differentiation of effective maintenance activities based on the cause of the latent failure. As an example, consider the startup failure mode of a motor-driven pump (failure rate $\lambda=7.8 \mathrm{E}-08[1 / \mathrm{h}]$ ) and two possible failure causes-a sticking of the sliding portion or the deterioration of consumables. If the relative contribution of these two causes to startup failure is 9:1 (that is, the ratio of the number of times the former was the cause of startup failure to the number of times the latter was the cause, based on the total number of cases of startup failure, is 9 to 1 ), we would set the failure rate for the sticking of the sliding portion to $\lambda=7.8 \mathrm{E}-08 \times 0.9=7.0 \mathrm{E}-08[1 / \mathrm{h}]$. When considering a trial operation of the pump as a maintenance activity, we assume that the trial operation cannot reduce the probability 
of failure due to the deterioration of consumables. On the other hand, we assume that the probability of failure due to the sticking of the sliding portion can be reduced.

\subsection{Maintenance Scheduling Model}

The proposed model formulation, together with the notation used in the formulation, is described below:

\section{Notation}

\section{Index sets.}

$I$ : set of failure cause indices.

$J$ : set of components.

$T$ : set of times.

\section{Parameters.}

$\lambda_{i j}(i \in I, j \in J)$ : failure rate of failure cause $i$ for component $j$.

$U^{*}$ : allowable value of the unreliability of the function of interest.

$C_{i j}(i \in I, j \in J)$ : monetary cost of maintenance for failure cause $i$ for component $j$.

$M$ : a large number.

\section{Variables.}

$x_{i j t}(i \in I, j \in J, t \in T): 0$ if maintenance is performed for failure cause $i$ of component $j$ at time $t$, and 1 otherwise.

$\Lambda_{i j t}(i \in I, j \in J, t \in T)$ : cumulative failure rate of failure cause $i$ for component $j$ at time $t$.

$u_{i j t}(i \in I, j \in J, t \in T)$ : unreliability associated with failure cause $i$ for component $j$ at time $t$.

$U_{t}(t \in T)$ : unreliability of the function of interest at time $t$.

$z_{i j t}(i \in I, j \in J, t \in T)$ : linearization variable for $x_{i j t} \Lambda_{i j t}$.

\section{$\underline{\text { Formulation }}$}

$$
\text { Minimize } \sum_{i \in I} \sum_{j \in J} \sum_{t \in T} C_{i j} x_{i j t}
$$

subject to

$$
\begin{gathered}
U_{t} \leq U^{*}, \forall t \in T, \\
u_{i j t}=1-\left(1-\Lambda_{i j, t-1}\right), \forall i \in I, \forall j \in J, \forall t \in T, \\
\Lambda_{i j 1}=\lambda_{i j}, \forall i \in I, \forall j \in J, \\
\Lambda_{i j t}=z_{i j, t-1}+\lambda_{i j}, \forall i \in I, \forall j \in J, t=2, \cdots, T, \\
z_{i j t} \leq M\left(1-x_{i j t}\right), \forall i \in I, \forall j \in J, \forall t \in T, \\
z_{i j t} \leq \Lambda_{i j t}, \forall i \in I, \forall j \in J, \forall t \in T, \\
\Lambda_{i j t}-M x_{i j t} \leq z_{i j t}, \forall i \in I, \forall j \in J, \forall t \in T, \\
x_{i j t} \in\{0,1\}, \forall i \in I, \forall j \in J, \forall t \in T, \\
\Lambda_{i j t}, u_{i j t}, z_{i j t} \geq 0, \forall i \in I, \forall j \in J, \forall t \in T,
\end{gathered}
$$

The objective function (1) minimizes the total monetary cost of maintenance activities over the lifetime of the plant. Constraint (2) restricts the unreliability of the function of interest to a value less than or equal to the value specified by the user. Constraint (3) calculates the unreliability associated with failure cause $i$ for component $j$ at time $t$. Constraints (4) and (5) 
compute the cumulative failure rate. The nonlinear expression $z_{i j t}=x_{i j t} \Lambda_{i j t}$ is equivalently expressed as the set of constraints (6)-(8). Constraint (9) is a binary constraint. Constraint (10) is a non-negative constraint.

\section{Numerical Experiments}

\subsection{Experimental Conditions}

To verify that the proposed model can successfully and automatically produce an optimal maintenance schedule, we applied the model to a single representative component-a motor-operated valve-constituting a safety-critical function. This illustrative application also allows us to demonstrate the ability of the model to provide the quantitative basis for evaluating the tradeoff between the reliability of safety-critical functions and the total maintenance cost considering the differences in the costs associated with each maintenance activity. The effect of cost on scheduling is assessed by comparing the scheduling results obtained when the objective is to minimize the total cost of the maintenance activities included in the schedule (Case 1) to the scheduling results when the objective is to minimize the total number of maintenance activities included in the schedule (Case 2). In Case 2, the following objective function replaces Eq. (1).

$$
\text { Minimize } \sum_{i \in I} \sum_{j \in J} \sum_{t \in T} x_{i j t}
$$

We assumed "fail to open/close" as the failure mode for the motor-operated valve. The possible causes for failure were identified as the sticking of the sliding portion of the valve, deterioration of the motor insulation, deterioration of the instrumentation and control equipment, and deterioration of the relevant consumables. The occurrence of any of these causes would result in the loss of the valve's opening and closing function. Thus, assuming that the failure rate is sufficiently low, $U_{t}$ in Eq. (2) can be written as follows:

$$
U_{t}=\sum_{i \in I} u_{i 1 t}, i=1, \cdots, 4, \forall t \in T .
$$

Table 1 lists the failure rates, effective maintenance activities, and maintenance costs for each failure cause included in the numerical experiments. To determine the failure rate for each cause, we referred to the available NUCIA data and based our determination on the concept presented in [5]. For the maintenance costs, the relative values were determined with reference to [8]. The cost of overhaul inspection was set to 1 . The evaluation period was set to 50 years and the allowable values for the unreliability of the opening and closing function was set to $U^{*}=1.0 \mathrm{E}-3$. These real-valued parameters were further scaled and converted to integer-valued parameters in order to frame the problem as a mixed-integer programming problem.

The mixed-integer programming problem described in Section 2.2 was solved using IBM ILOG CPLEX Optimization Studio version 12.10.0. The computational environment was an Intel Core i7-8500Y 1.50 GHz processor with 16.0 GB RAM.

\subsection{Results}

\subsubsection{Case 1. Minimizing the total cost of maintenance activities}

Figure 1 shows the time series of the cumulative failure rates of each failure cause in the optimal maintenance schedule produced when the objective was to minimize the total cost 
Table 1: Failure rates, effective maintenance activities and their costs for each failure cause

\begin{tabular}{llllc}
\hline \hline Component & Failure cause & $\begin{array}{l}\text { Failure rate } \\
{[1 / \mathrm{h}]}\end{array}$ & $\begin{array}{l}\text { Effective main- } \\
\text { tenance activity }\end{array}$ & Cost \\
\hline \hline $\begin{array}{l}\text { Motor-operated } \\
\text { valve }\end{array}$ & Sticking of sliding portion & $4.69 \mathrm{E}-09$ & $\begin{array}{l}\text { Overhaul in- } \\
\text { spection }\end{array}$ & 1 \\
& $\begin{array}{l}\text { Motor insulation deteriora- } \\
\text { tion }\end{array}$ & $4.69 \mathrm{E}-10$ & Replacement & 10 \\
\cline { 2 - 5 } & $\begin{array}{l}\text { Instrumentation \& control } \\
\text { equipment deterioration }\end{array}$ & & & \\
& $\begin{array}{l}\text { Deterioration of consum- } \\
\text { ables }\end{array}$ & $4.69 \mathrm{E}-10$ & Replacement & 10 \\
& & & & 10 \\
\hline \hline
\end{tabular}

associated with the maintenance activities included in the schedule. In this case, the less costly overhaul inspection for the sticking of the sliding portion was performed at relatively short and irregular intervals. In contrast, the more costly replacement for instrumentation and control equipment deterioration was performed at intervals of approximately seven years. Replacements for motor insulation deterioration and the deterioration of consumables were not performed during the period considered.

Figure 2 shows the time series of the unreliability of the opening and closing function of a motor-operated valve. As indicated, the function's unreliability in the optimal maintenance schedule did not exceed the allowable upper limit.

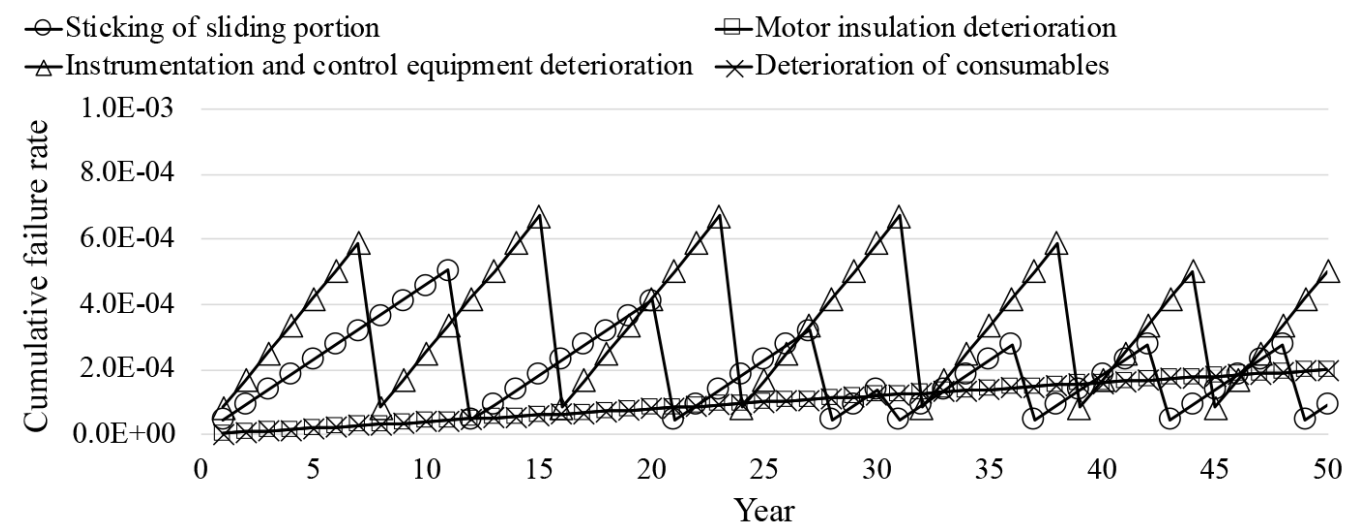

Figure 1: Time series of the cumulative failure rates for each failure cause: Case 1 (Minimizing the total cost of maintenance activities)

\subsubsection{Case 2. Minimizing the total number of maintenance activities}

Figure 3 shows the time series of the cumulative failure rates of each failure cause in the optimal maintenance schedules that were produced when the objective was to minimize the total number of maintenance activities included in the schedule. Here, the number of less costly overhaul inspections for the sticking of the sliding portion is reduced relative to Case 1 and the activity is performed at approximately 10-year intervals. Moreover, the number 


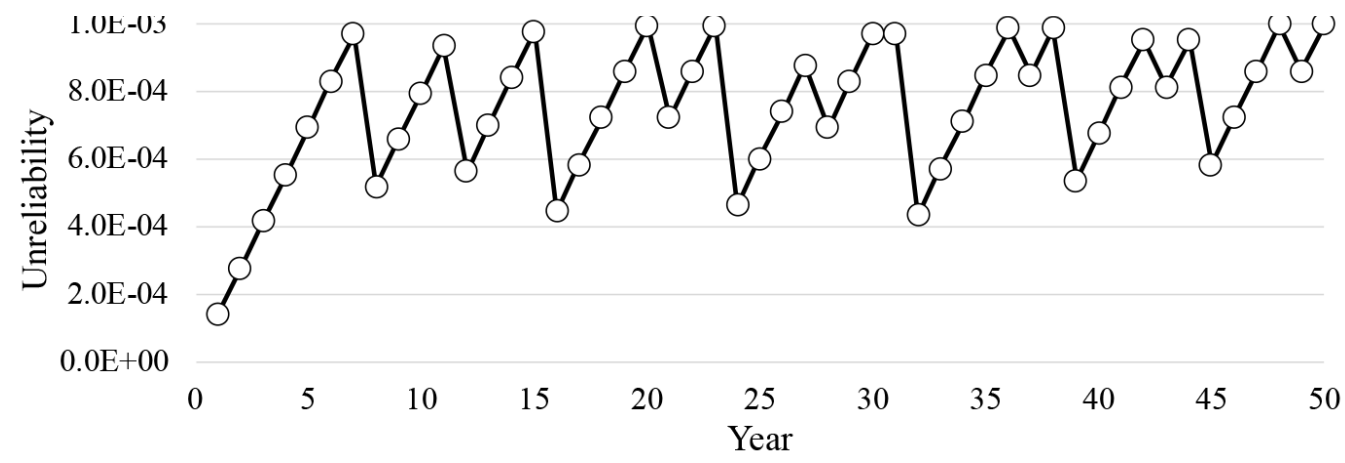

Figure 2: Time series of the unreliability of the opening and closing function of a motoroperated valve: Case 1 (Minimizing the total cost of maintenance activities)

of more costly replacements for instrumentation and control equipment deterioration is slightly increased and one replacement for the deterioration of consumables is performed.

Figure 4 shows the time series of the unreliability of the opening and closing function of a motor-operated valve. As in Case 1, the function's unreliability in the optimal maintenance schedule did not exceed the allowable upper limit.

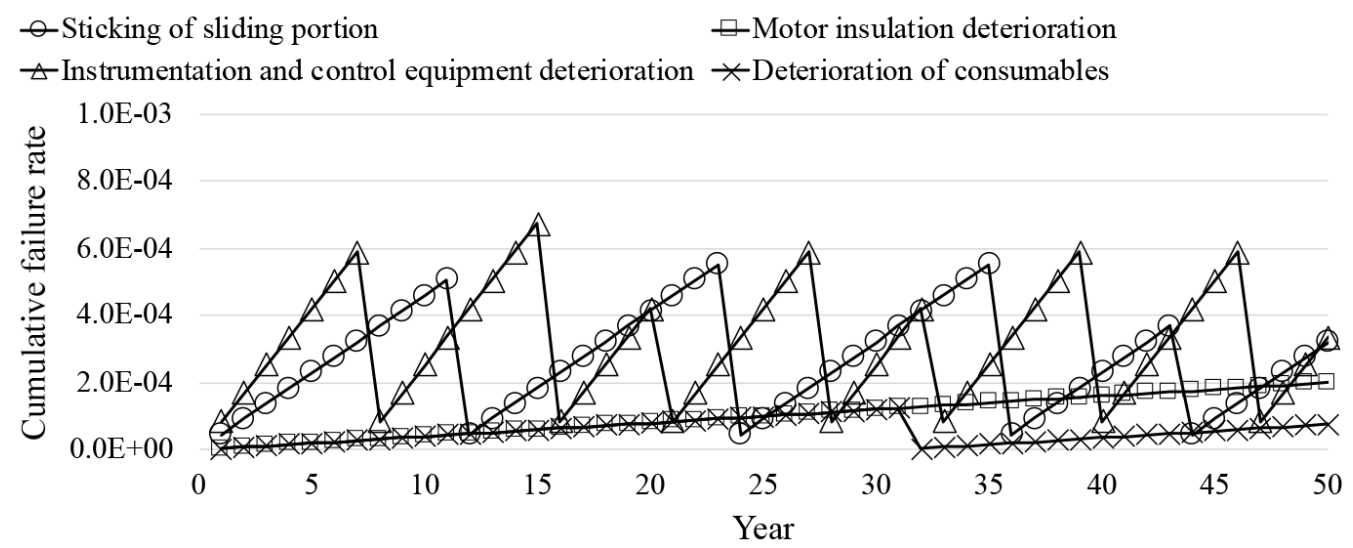

Figure 3: Time series of the cumulative failure rates for each failure cause: Case 2 (Minimizing the total number of maintenance activities)

\section{Discussion}

Tables 2 and 3 show the optimal maintenance schedules, together with the total number and total cost of maintenance activities in the schedule, for Cases 1 and 2, respectively. As shown, minimizing the total maintenance cost by considering the differences in the cost associated with the various maintenance activities reduces the total cost by $20 \%$ (67 vs. 84 ) while keeping the total maintenance frequency close to the minimum value (13 vs. 12).

The proposed model enables us to quantitatively evaluate the effect of the allowable unreliability value for the safety-critical function on the maintenance schedule and to assess 


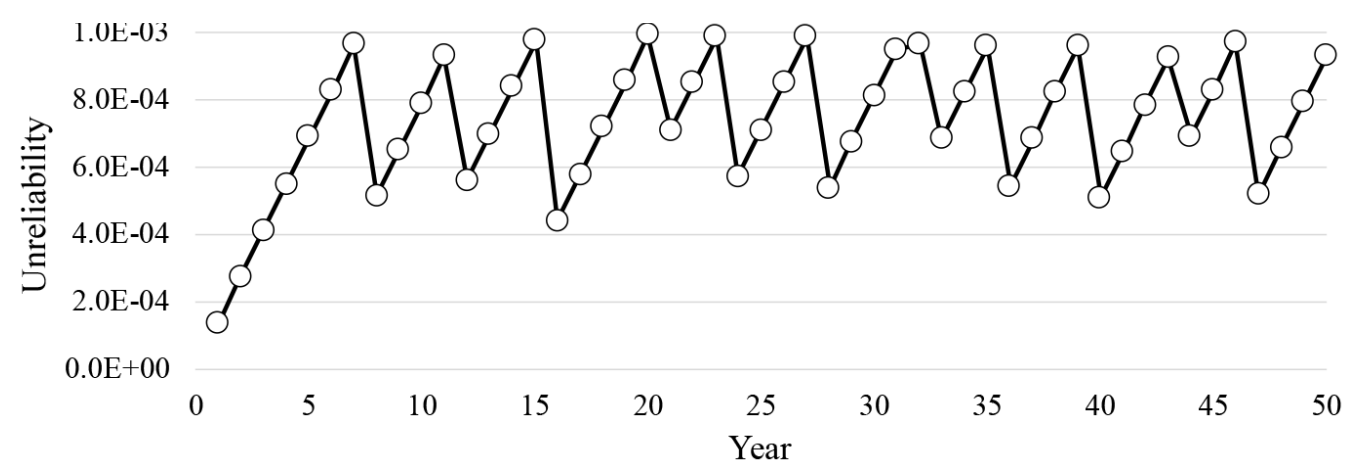

Figure 4: Time series of the unreliability of the opening and closing function of a motoroperated valve: Case 2 (Minimizing the total number of maintenance activities)

Table 2: Optimal maintenance schedule: Case 1 (Minimizing the total cost of maintenance activities)

\begin{tabular}{|c|c|c|c|c|c|c|}
\hline Failure cause & $\begin{array}{l}\text { Effective main- } \\
\text { tenance activity }\end{array}$ & $\overline{\text { Cost }}$ & $\begin{array}{l}\text { Years of mai- } \\
\text { ntenance }\end{array}$ & $\begin{array}{l}\text { Freq- } \\
\text { uency }\end{array}$ & $\begin{array}{l}\text { Total } \\
\text { number }\end{array}$ & $\begin{array}{l}\text { Total } \\
\text { cost }\end{array}$ \\
\hline Sticking of sliding portion & $\begin{array}{l}\text { Overhaul in- } \\
\text { spection }\end{array}$ & $\overline{11}$ & $\begin{array}{l}11,20,27,30, \\
36,42,48\end{array}$ & $\overline{77}$ & 13 & 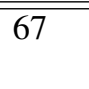 \\
\hline $\begin{array}{l}\text { Motor insulation deterio- } \\
\text { ration }\end{array}$ & Replacement & 10 & - & 0 & & \\
\hline $\begin{array}{l}\text { Instrumentation \& control } \\
\text { equipment deterioration }\end{array}$ & Replacement & 10 & $\begin{array}{l}7,15,23,31 \\
38,44\end{array}$ & 6 & & \\
\hline $\begin{array}{l}\text { Deterioration of consum- } \\
\text { ables }\end{array}$ & Replacement & 10 & - & 0 & & \\
\hline
\end{tabular}

the tradeoff between the reliability of safety-critical functions and the maintenance cost. Figure 5 shows the relationship between the allowable unreliability value of the opening and closing function and the total cost of the maintenance activities for the two illustrative cases. As can be seen in the figure, Case 1, where the cost differences between the various maintenance activities are considered, produced schedules with 14-80\% lower total maintenance costs compared to Case 2 for each of the allowable unreliability values tested.

\section{Conclusion}

We have proposed a maintenance-scheduling model that minimizes the total cost of the maintenance activities included in an NPP maintenance schedule while ensuring the reliability of the system's safety-critical functions. The maintenance-scheduling problem was formulated as a mixed-integer programming problem in which the user is able to differentiate the costs associated with the various maintenance activities, depending on the type of maintenance involved.

Applying the model to a single representative component (a motor-operated valve), we 
Table 3: Optimal maintenance schedule: Case 2 (Minimizing the total number of maintenance activities)

\begin{tabular}{|c|c|c|c|c|c|c|}
\hline Failure cause & $\begin{array}{l}\text { Effective main- } \\
\text { tenance activity }\end{array}$ & Cost & $\begin{array}{l}\text { Years of mai- } \\
\text { ntenance }\end{array}$ & $\begin{array}{l}\text { Freq- } \\
\text { uency }\end{array}$ & $\begin{array}{l}\text { Total } \\
\text { number }\end{array}$ & $\begin{array}{l}\text { Total } \\
\text { cost }\end{array}$ \\
\hline Sticking of sliding portion & $\begin{array}{l}\begin{array}{l}\text { Overhaul in- } \\
\text { spection }\end{array} \\
\end{array}$ & 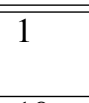 & $\overline{111,23,35,43}$ & 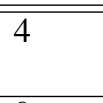 & 12 & 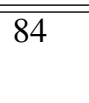 \\
\hline $\begin{array}{l}\text { Motor insulation deterio- } \\
\text { ration }\end{array}$ & Replacement & 10 & - & 0 & & \\
\hline $\begin{array}{l}\text { Instrumentation \& control } \\
\text { equipment deterioration }\end{array}$ & Replacement & 10 & $\begin{array}{l}7,15,20,27 \\
32,39,46\end{array}$ & 7 & & \\
\hline $\begin{array}{l}\text { Deterioration of consum- } \\
\text { ables }\end{array}$ & Replacement & 10 & 31 & 1 & & \\
\hline
\end{tabular}

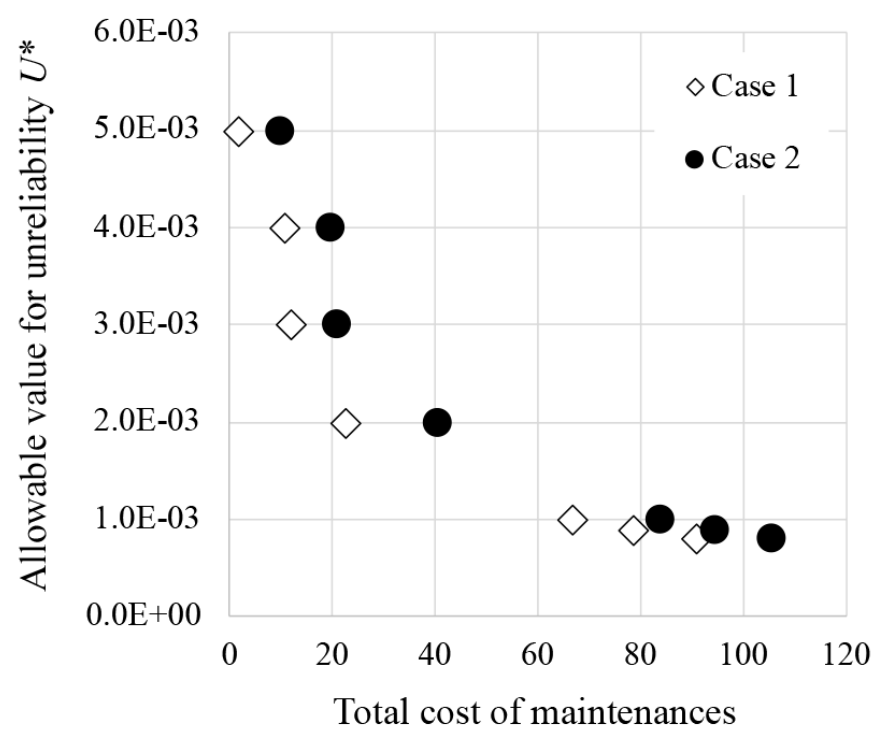

Figure 5: Tradeoff between the unreliability of the opening and closing function and the total cost associated with the maintenance of a motor-operated valve 
showed that the proposed model is capable of producing an optimal schedule in which total cost is minimized and system unreliability is constrained within a pre-set upper boundary. Our proposed formulation enables the user to quantitatively determine the effect of the allowable unreliability value on the schedule and to evaluate the tradeoff between the reliability of safety-critical functions and maintenance cost. By considering the differences in the cost of each maintenance activity in our illustrative example, we were able to construct a superior schedule with a lower total maintenance cost for each of the allowable unreliability values tested.

Future efforts will include expanding the maintenance scheduling target from a single component to all the components of a safety-critical function.

\section{Acknowledgments}

This work was supported in part by the Grant-in-Aid for Young Scientists (B) (Grant Number JP17K14912) from the Japan Society for the Promotion of Science.

\section{References}

[1] N. Prajapat, A. Tiwari, X.P. Gan, N.Z. Ince, and W. Hutabarat, "Preventive maintenance scheduling optimization: A review of applications for power plants," Advances in Through-life Engineering Services, Decision Engineering, L. Redding, R. Roy, and A. Shaw, eds., Springer, 2017, pp. 397-415.

[2] M. Harunuzzaman and T. Aldemir, "Optimization of standby safety system maintenance schedules in nuclear power plants," Nuclear Technology, vol. 113, no. 3, 1996, pp. 354-367.

[3] C.M.N.A. Pereira, C.M.F. Lapa, A.C.A. Mol, and A.F. da Luz, "A particle swarm optimization (PSO) approach for non-periodic preventive maintenance scheduling programming," Progress in Nuclear Energy, vol. 52, no. 8, 2010, pp. 710-714.

[4] M. Aghaie, A. Norouzi, A. Zolfaghari, A. Minuchehr, Z.M. Fard, and R. Tumari, "Advanced progressive real coded genetic algorithm for nuclear system availability optimization through preventive maintenance scheduling," Annals of Nuclear Energy, vol. 60, 2013, pp. 64-72.

[5] K. Demachi, H. Miyano, S. Arai, M. Suzuki, T. Itoi, A. Yamaguchi, K. Murakami, and M. Matsumoto, "Maintenance index for system safety assessment for aging nuclear power plant," E-Journal of Advanced Maintenance, vol. 7, no. 3, 2015, pp. 199-205.

[6] M. Ito and M. Suzuki, "Optimal maintenance scheduling in nuclear power plants via linear programming considering the relationship between the failure cause and maintenance type," E-Journal of Advanced Maintenance, vol. 11, no. 4, 2020, pp. 153-162.

[7] Japan Nuclear Safety Institute, NUClear Information Archives (NUCIA); http://www.nucia.jp/index.html (In Japanese).

[8] Y. Ling, K. Maki, N. Yusa, and K. Miya, "Development of the optimization model for TBM time intervals in maintenance methods combined TBM and CBM," Transactions of the Atomic Energy Society of Japan, vol. 6, no. 3, 2007, pp. 312-319 (In Japanese). 